\title{
Effect of Selected Surfactants on Kinetics of Meloxicam Release from Rectal Suppositories
}

\author{
B. SZULC-MUSIOŁ*, L. BUŁAŚ AND B. DOLIŃSKA \\ Department of Pharmaceutical Technology, School of Pharmacy and the Division of Laboratory Medicine, Medical University \\ of Silesia, 41-200 Sosnowiec, Poland
}

Szulc-Musioł et al.: Effect of Selected Surfactants on Kinetics of Meloxicam Release

\begin{abstract}
The use of surfactants in suppository formulations has been suggested to improve the bioavailability of poorly soluble drugs. In the present study, different kinds of surfactants were investigated to understand their influence on meloxicam release from suppositories formulated with a lipophilic base. Tween 80, Span 80, soy lecithin and sodium lauryl sulphate were the surfactants used in this study. The suppositories were prepared in a recipe mixer using Witepsol H15 and cacao oleum as a base. The suppositories with and without the addition of surfactants were examined using physicochemical tests according to the Polish Pharmacopeia, the uniformity of mass of single-dose preparation test, the content uniformity test, the softening time determination of lipophilic suppositories test, the disintegration test of suppositories, and the dissolution test. All the prepared formulations complied with the pharmacopeia requirements. The prepared suppositories were evaluated for in vitro drug release immediately after preparation and after storage. The results revealed that the bioavailability of meloxicam was to $36 \%$ from suppositories formulated with Witepsol $\mathrm{H} 15$ and $23.4 \%$ those formulated with cacao oleum. Addition of surfactants to the suppository base significantly influenced both the amount and rate of meloxicam released into the phosphate buffer. The highest release rate of meloxicam was observed with the formulation prepared on a Witepsol $\mathrm{H15}$ base with Tween 80. Present results have confirmed the possibility of using surfactants in suppository formulations, in order to improve the dissolution rate of meloxicam in vitro. As a consequence, a faster onset of pharmacodynamic action and better therapeutic effects of the medication can be obtained.
\end{abstract}

Key words: Meloxicam, surfactant, suppositories, dissolution study

The therapeutic effect of a drug depends on its concentration at the site of action, where the interaction between a molecule of drug substance and its appropriate receptor takes place. The factors that affect the release and absorption of the drug from suppositories are, anatomical and physiological conditions at the site of application, dosage, the physicochemical properties of the active substance including its solubility, type of base, and the properties of other auxiliary substances, as well as the technology used for producing a preparation ${ }^{[1,2]}$.

Meloxicam is an oxicam, which has a low COX-2/ COX-1 ratio, with the inhibitory effect more focused on the inflammatory proteins (COX-2) with relatively little effect on the homoeostatic proteins (COX-1). Meloxicam is a frequently prescribed nonsteroidal antiinflammatory drug (NSAID) in the USA and is prescribed for the treatment of osteoarthritis (OA),

*Address for correspondence

E-mail: bszulc@sum.edu.pl

November-December 2019 rheumatoid arthritis (RA) and juvenile $\mathrm{RA}^{[3,4]}$. It is also one of the few NSAIDs approved for use in animals ${ }^{[4]}$. Administration of meloxicam compared to other NSAIDs reduces the risk of cardiovascular and renal incidences, especially at higher doses and upon long term use $\mathrm{e}^{[5]}$. Meloxicam is a Biopharmaceutical Classification System class II drug ${ }^{[6]}$. Its lipophilicity is measured using LogP, which is 3.43 . The solubility and dissolution rate of meloxicam in acidic media is very poor, and thus, its bioavailability is also low. In addition, poor solubility of meloxicam in gastric juices causes

This is an open access article distributed under the terms of the Creative Commons Attribution-NonCommercial-ShareAlike 3.0 License, which allows others to remix, tweak, and build upon the work non-commercially, as long as the author is credited and the new creations are licensed under the identical terms

Accepted 27 October 2019

Revised 02 August 2019

Received 03 October 2018

Indian J Pharm Sci 2019;81(6):1115-1121 
an increased local concentration of the drug. This, in turn, can result in adverse effects, such as irritation and ulceration of the stomach mucosa, and even perforation of the gastric wall[ ${ }^{[7]}$. Therefore, a number of studies focussed on the search for effective NSAIDs with reduced adverse gastrointestinal reactions.

In the dissolution process of sparingly soluble substances, an important role among auxiliary substances is played by surfactants ${ }^{[8,9]}$. The presence of surfactants in suppositories for rectal administration can cause some changes in the properties of the suppository base ${ }^{[3,10]}$. In particular, adding a surfactant to suppositories can facilitate the spread of the suppository bases in the rectum. This affects the size of the absorptive surface area available to the $\operatorname{drug}^{[11,12]}$ Numerous studies have confirmed the beneficial effect of surfactants on the liberation of drugs from suppositories ${ }^{[9,13-15]}$. However, no publication was found describing the effect of surfactants on the release of meloxicam from suppositories.

Meloxicam was selected in this study as a model drug, because it possesses appropriate physicochemical properties for trans-administration by the rectal route (low molecular weight, low polarity and low daily therapeutic dose). It has been reported that meloxicam formulations (ocular, rectal and dermal) exhibit good local tissue tolerability ${ }^{[4,11]}$. Moreover, administration of meloxicam in the form of suppositories can reduce many undesirable outcomes, the first-pass effect included ${ }^{[11]}$. A study reported by Carrabba et al. confirmed that meloxicam $15 \mathrm{mg}$ suppositories showed excellent local tolerability accompanied by good safety and efficacy over a three-week period in patients with $\mathrm{OA}^{[10]}$.

In earlier research reported from our department, it was shown that meloxicam release from rectal suppositories prepared with lipophilic bases proceeds very slowly and incompletely, in comparison with those prepared with hydrophilic ones. After 120 min about $23 \%$ of meloxicam was released from suppositories formulated on a cacao oleum base, while $36 \%$ was released from the suppositories formulated on Witepsol $\mathrm{H} 15^{[16]}$. At the same time, about $95 \%$ of meloxicam was released into the acceptor medium from suppositories prepared on polyethylene glycol (PEG) bases, and $65 \%$ was released from Movalis suppositories, the reference preparation. These results are similar to the data obtained in a study of carbamazepine release from suppositories formulated on lipophilic bases ${ }^{[17]}$.

The aim of this study was the evaluation of the influence of the selected surfactants, Tween 80, Span
80, soy lecithin and sodium lauryl sulfate (SLS) on the physicochemical parameters and pharmaceutical availability of meloxicam from suppositories formulated on a lipophilic base.

\section{MATERIALS AND METHODS}

Meloxicam was purchased from Merck, Germany. Cacao oleum (Farma Cosmetic Kraków, Poland) and Witepsol H15 (GlaxoSmithKline Pharmaceuticals) were used as the basis for suppository preparation. Tween 80 , Span 80, soy lecithin, and SLS were products of Sigma-Aldrich Chemie GmbH, Schnelldorf, Germany. All other chemicals were of analytical grade.

\section{Formulation of rectal suppositories:}

In the study, rectal suppositories weighing $2 \mathrm{~g}$ and containing $15 \mathrm{mg}$ of meloxicam were prepared. Cacao oleum and Witepsol H15 were used as a lipophilic base. The suppositories were formulated by adding meloxicam, with or without a surfactant (Tween 80, Span 80 , soy lecithin and SLS), at a concentration of $2 \% \mathrm{w} / \mathrm{w}$. The suppositories were prepared using a mixer (Unquator ${ }^{\circledR} 2100$, Gato, Poland). Meloxicam, auxiliary substances and the bases were placed in a container, homogenized for $7 \mathrm{~min}$ at a speed of $2000 \mathrm{rpm}$ and then the homogenous mass was poured into plastic moulds and put into the refrigerator so that the suppositories could solidify.

Prior to the preparation of the suppositories, the mould was standardized. The drug present in the suppository in a solid form occupies a certain volume, therefore the amount of medium for preparing a suppository of a given mass should be correspondingly smaller. The following formula was used to calculate the amount of base, $\mathrm{M}=\mathrm{F}-(\mathrm{f} \times \mathrm{s})$, where $\mathrm{M}$ is the total amount of base needed to produce the planned amount of suppositories, $\mathrm{F}$ is the amount of substrate $(\mathrm{g})$ completely filling the mould, taking into account the number of suppositories, $\mathrm{f}$ is displacement factor, $\mathrm{s}$ is the amount of meloxicam in grams per number of suppositories to be made. For suppositories made with cacao oleum base, the meloxicam displacement factor f was 0.89 and for Witepsol H15 it was 0.65 . The obtained suppositories underwent quality testing in compliance with Polish Pharmacopoeia $11^{\text {th }}$ edition (FP 11th) $)^{[18]}$.

\section{Evaluation of suppositories:}

For the weight variation, twenty suppositories were weighed and the average weight was calculated. Then all the suppositories were individually weighed and 
the variation from the average was calculated. No suppositories should deviate from average weight by more than $5 \%$. Content uniformity was also calculated. The suppositories were melted with gentle heating in a water bath. The drug content was determined on 10 suppositories of each formulation. A randomly selected suppository was taken in a $100 \mathrm{ml}$ volumetric flask and was melted with gentle heating in a water bath in the presence of phosphate buffer ( $\mathrm{pH}$ 7.8). The flask was shaken for $1 \mathrm{~h}$ on a gyratory shaker at $150 \mathrm{rpm}$. The solution was filtered through a PVDF membrane filter (Sartorius $0.2 \mu \mathrm{m}$ ); the filtrate was diluted suitably and absorbance was measured on a Cecil CE 3021 UV/Vis spectrophotometer (Cecil Instruments) at $363.5 \mathrm{~nm}$ against a blank prepared using the respective suppositories without the drug.

An Erweka hardness tester (STB, Germany) was used to measure the resistance of the suppositories to crushing $(\mathrm{n}=10)$. Disintegration time was determined in a water maintained at $37 \pm 0.5^{\circ}$ using a disintegration apparatus (ST30 Erweka, Germany). Three suppositories were put into a disintegration apparatus and the disintegration time was measured. The softening time was determined using the apparatus described in the FP 11 th $n=3)^{[18]}$.

\section{In vitro dissolution testing:}

The dissolution test was carried out according to the rotating basket method using the dissolution test system DT-600 (Erweka, Germany). Nine hundred millilitres of phosphate buffer ( $\mathrm{pH}$ 7.8) in a vessel was used as the test medium. The basket rotation speed was 50 rpm. Samples of $3 \mathrm{ml}$ volume were collected at 10, 20, $30,40,60,75,90,105$, and $120 \mathrm{~min}$ of the test. The concentration of meloxicam was determined on a UV/ Vis spectrophotometer at $363.5 \mathrm{~nm}$ (fig. 1).

The results of the release tests were analysed with the zero order model (dQ'/dt), Higuchi model (dQ'/ $\left.\mathrm{dt}=\mathrm{k} / 2 \mathrm{Q}^{\prime}\right)$ and the first order model $\left(\mathrm{dQ} / \mathrm{dt}=\mathrm{k}\left(\mathrm{Q}_{0}-\mathrm{Q}^{\prime}\right)\right.$, where $\left(\mathrm{Q}_{0}-\mathrm{Q}^{\prime}\right)$ is the residual drug still to be released and $\mathrm{Q}_{0}$ is the initial amount of the active substance in the suppositories ${ }^{[19,20]}$. The model that produced the highest correlation among the suppository preparations was used for the assessment of the drug release rate.

\section{Effect of storage on the release of meloxicam suppositories:}

Meloxicam suppositories were shelf-stored in the temperature range of $15-25^{\circ}$ for 3 mo. After this time, the appearance of the stored suppositories was evaluated and a dissolution study of meloxicam was performed.

\section{Statistical analysis:}

Data were analysed by the one-way ANOVA analysis of variance with post hoc Dunnett's test using Statistica 12 (STATSOFT; Statistica, Tulsa, OK, USA) software.

\section{RESULTS AND DISCUSSION}

In the visual assessment, the prepared suppositories were characterized by a uniform color and had a smooth surface without any fissures or contraction holes. The formulated suppositories complied with the Pharmacopoeia's requirements regarding the physicochemical properties (Table 1). Suppositories prepared with a base of Witepsol H15 had a significantly $(\mathrm{p}<0.01)$ longer softening time and higher hardness compared to suppositories made from cacao oleum. The results showed that in case of the suppositories formulated with addition of surfactants, the same significant decrease in their softening time was observed. Moreover, the addition of the surfactants induced a significant increase in hardness of the suppositories irrespective of the base applied. The results are in agreement with those previously reported ${ }^{[21]}$.

The release of meloxicam from cacao oleum and Witepsol H15 suppository bases is illustrated in figs. $2 \mathrm{~A}$ and $\mathrm{B}$. The results indicated that meloxicam release from the Witepsol H15 base was superior to that from the cacao oleum. The results of the study on the release kinetics of meloxicam from suppositories showed that this process mainly occurred according to first order kinetics, with the exception of the suppositories prepared with cacao oleum without the surfactant additives, from which the drug substance was released according to zero order kinetics (Table 2).

Based on these results it was confirmed that a significantly $(\mathrm{p}<0.01)$ smaller amount of meloxicam was released (except for suppositories with SLS) and a significantly $(p<0.01)$ lower softening time was

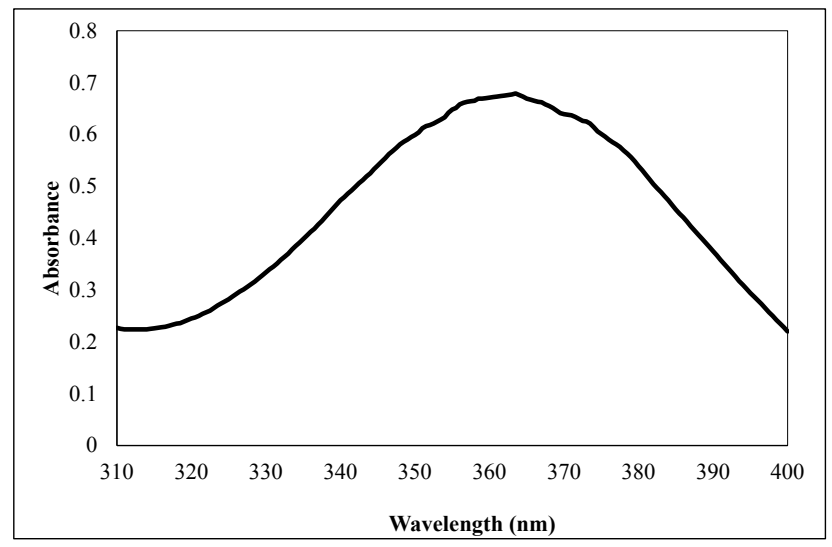

Fig. 1: Meloxicam spectrum in phosphate buffer 
TABLE 1: PHYSICOCHEMICAL PROPERTIES OF MELOXICAM SUPPOSITORIES

\begin{tabular}{lccccc}
\hline Formulations & $\begin{array}{c}\text { Uniformity } \\
\text { of mass }(\mathrm{g}, \mathrm{n}=20)\end{array}$ & $\begin{array}{c}\text { Drug content } \\
\left(\%^{*}, \mathrm{n}=10\right)\end{array}$ & $\begin{array}{c}\text { Disintegration time } \\
(\mathrm{min}, \mathrm{n}=3)\end{array}$ & $\begin{array}{c}\text { Softening } \\
\text { time }(\mathrm{min}, \mathrm{n}=3)\end{array}$ & $\begin{array}{c}\text { Hardness } \\
(\mathbf{k g}, \mathrm{n}=10)\end{array}$ \\
\hline CO & $2.03 \pm 0.01$ & $97.47 \pm 2.51$ & $4.44 \pm 0.11$ & $6.64 \pm 0.40$ & $2.20 \pm 0.17$ \\
CO+T80 & $2.12 \pm 0.01$ & $98.17 \pm 1.37$ & $3.57 \pm 0.44$ & $5.01 \pm 0.42$ & $4.50 \pm 0.38$ \\
CO+S80 & $2.23 \pm 0.014$ & $98.47 \pm 1.84$ & $3.67 \pm 0.42$ & $5.29 \pm 0.15$ & $3.50 \pm 0.29$ \\
CO+SL & $2.26 \pm 0.01$ & $98.40 \pm 1.87$ & $3.84 \pm 0.40$ & $5.00 \pm 0.52$ & $4.00 \pm 0.27$ \\
CO+SLS & $2.04 \pm 0.01$ & $97.47 \pm 2.51$ & $3.44 \pm 0.11$ & $6.64 \pm 0.40$ & $3.20 \pm 0.19$ \\
W-H15 & $2.12 \pm 0.01$ & $97.67 \pm 1.37$ & $9.57 \pm 0.44^{* *}$ & $10.01 \pm 0.42^{* *}$ & $4.50 \pm 0.35^{* *}$ \\
W-H15+T80 & $2.11 \pm 0.01$ & $97.67 \pm 1.37$ & $3.57 \pm 0.44$ & $8.01 \pm 0.42^{* *}$ & $5.50 \pm 0.38^{* *}$ \\
W-H15+S80 & $2.23 \pm 0.014$ & $98.47 \pm 1.84$ & $3.37 \pm 0.42$ & $9.29 \pm 0.15^{* *}$ & $5.80 \pm 0.41^{* *}$ \\
W-H15+SL & $2.26 \pm 0.01$ & $98.40 \pm 1.87$ & $3.74 \pm 0.40$ & $9.00 \pm 0.52^{* *}$ & $6.00 \pm 0.51^{* *}$ \\
W-H15+SLS & $2.03 \pm 0.01$ & $97.47 \pm 2.51$ & $4.44 \pm 0.11^{* *}$ & $7.64 \pm 0.40^{* *}$ & $5.20 \pm 0.47^{* *}$ \\
\hline
\end{tabular}

*\% of the theoretical content; ${ }^{* *} \mathrm{p}<0.01$ as compared to the suppositories formulated CO; abbreviation used were cacao oleum (CO); Witepsol H15 (W-H15); Tween 80 (T80); Span 80 (S80); soy lecithin (SL) and sodium lauryl sulfate (SLS)

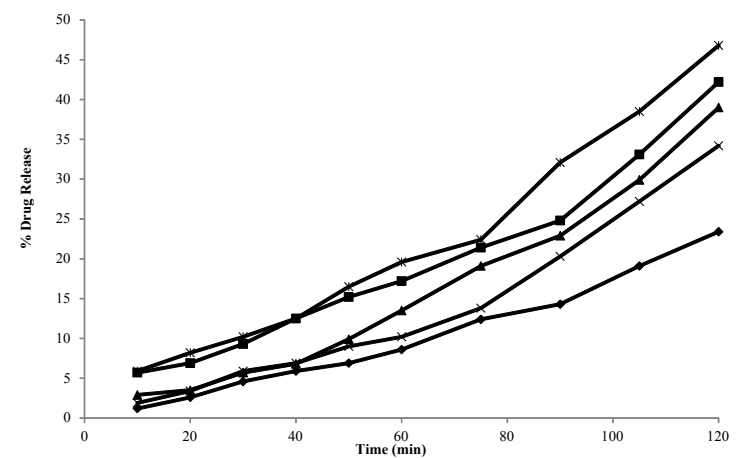

A.

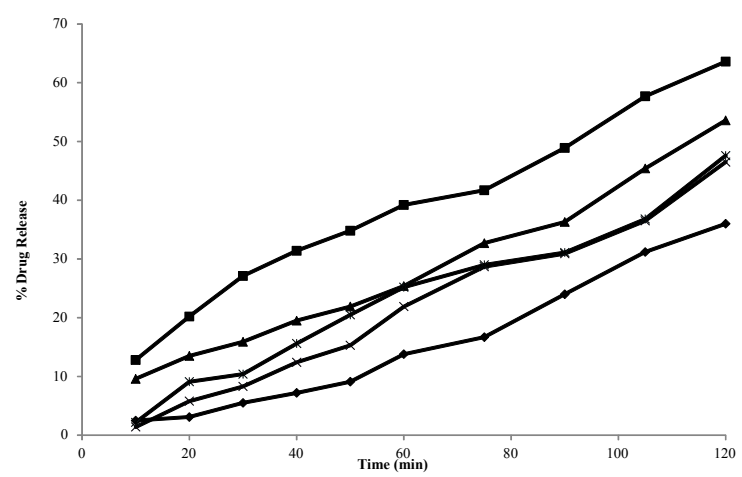

B.

Fig. 2: Effect of surfactants on the release of meloxicam from suppositories

The effect of surfactants on the release profile of meloxicam from suppositories prepared with A. cacao oleum (-४), cacao oleum+Tween 80 (一- -), cacao oleum+Span 80 ( $-\Delta-)$, cacao oleum+soy lecithin (-×-) and cacao oleum+sodium lauryl sulfate (-*-); B. Witepsol H15 (-४), Witepsol H15+Tween 80 (-匹-), Witepsol H15+Span 80 (一 $-\Delta)$, Witepsol H15+soy lecithin (-×-) and Witepsol H15+sodium lauryl sulfate (-*-)

found in the case of cacao oleum than of Witepsol H15 suppositories. In the case of lipophilic bases, usually drug release corresponds to the melting process in rectal temperature. The release of meloxicam from Witepsol H15 was significantly faster than that from cacao oleum. Application of Tween 80, Span 80, soy lecithin and SLS caused a significant $(\mathrm{p}<0.01)$ increase by $18.01,16.80$,
14.81 and $20 \%$, respectively in meloxicam release from suppositories formulated with cacao oleum, compared to those prepared without those surfactants.

Similarly, suppositories formulated with Witepsol H15 base showed a significant $(\mathrm{p}<0.01)$ increase in meloxicam release while the release was increased by $17.68 \%$ with Tween $80,14.9 \%$ with Span $80,12.93 \%$ with soy lecithin and $13.23 \%$ with SLS, in comparison to that from the suppositories prepared without these surfactants.

It has been demonstrated that there were no adverse effects of shelf storage on the prepared suppositories, with regard to the amount of meloxicam released from each of the tested formulations. In addition, after the usual storage time, no visual changes were observed in the prepared suppositories (fig. 3).

Many studies corroborate the clinical relevance of rectal drug therapy, which has been reported to exceed oral values in many cases, and for some drugs the rectal route can be an alternative to parental administration ${ }^{[22-25]}$. In Poland, preparations in the form of suppositories are often used. Suppositories prepared using a pharmaceutical prescription mixer are of good quality ${ }^{[26]}$. It was found that the uniformity of mass of the single-dose preparation test of all series of suppositories did not exceed $1 \%$ and the content uniformity of single-dose preparations in each series of suppositories did not exceed $1 \%$.

Cacao oleum and Witepsol H15 were selected as suppository bases for the preparation of the suppositories with meloxicam. Cacao oleum is a well-known base used mainly in pharmaceutical preparations. This is the only base available in pharmacies in Poland, and is used routinely for the preparation of suppositories and globules. It is bland and non-irritating to sensitive membrane tissues but it is more difficult to obtain the 
TABLE 2: KINETIC PARAMETERS FOR ANALYSIS OF FORMULATIONS RELEASE DATA

\begin{tabular}{|c|c|c|c|c|c|c|}
\hline Formulations & $\begin{array}{c}\text { Amount } \\
\text { of release meloxicam (\%) }\end{array}$ & $\begin{array}{c}\mathbf{R}^{2} \\
\text { Zero Order }\end{array}$ & $\begin{array}{c}\mathbf{R}^{2} \\
\text { First order }\end{array}$ & $\begin{array}{c}\mathbf{R}^{2} \\
\text { Higuchi-model }\end{array}$ & $\begin{array}{c}\text { Release } \\
\text { rate constant } \\
\mathbf{k}\left(\mathbf{h}^{-1}\right)\end{array}$ & $\begin{array}{c}\text { Release } \\
\text { half-time } \\
\mathrm{t}_{0.5}(\mathrm{~h})\end{array}$ \\
\hline $\mathrm{CO}$ & 23.40 & 0.978 & 0.909 & 0.919 & 10.259 & 4.87 \\
\hline $\mathrm{CO}+\mathrm{T} 80$ & 42.22 & 0.962 & 0.976 & 0.895 & 0.357 & 1.94 \\
\hline $\mathrm{CO}+\mathrm{S} 80$ & 39.40 & 0.961 & 0.973 & 0.883 & 0.341 & 2.03 \\
\hline $\mathrm{CO}+\mathrm{SL}$ & 34.72 & 0.945 & 0.956 & 0.863 & 0.301 & 2.03 \\
\hline $\mathrm{CO}+\mathrm{SLS}$ & 46.88 & 0.970 & 0.981 & 0.902 & 0.405 & 1.71 \\
\hline W-H15 & $36.0^{* *}$ & 0.957 & 0.964 & 0.895 & $0.319^{* *}$ & $2.17^{* *}$ \\
\hline W-H15+T80 & 63.66 ** & 0.984 & 0.891 & 0.981 & $0.604^{* *}$ & $1.14^{* *}$ \\
\hline $\mathrm{W}-\mathrm{H} 15+\mathrm{S} 80$ & $53.67^{* *}$ & 0.976 & 0.984 & 0.931 & $0.463^{* *}$ & $1.49^{* *}$ \\
\hline $\mathrm{W}-\mathrm{H} 15+\mathrm{SL}$ & $46.57^{* *}$ & 0.816 & 0.989 & 0.958 & $0.444^{* *}$ & $1.55^{* *}$ \\
\hline W-H15+SLS & 47.64 & 0.781 & 0.978 & 0.966 & 0.453 & 1.52 \\
\hline
\end{tabular}

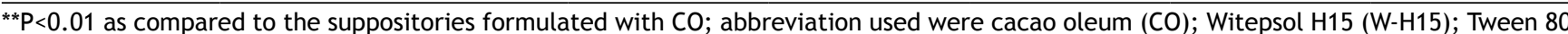
(T80); Span 80 (S80); soy lecithin (SL) and sodium lauryl sulfate (SLS)
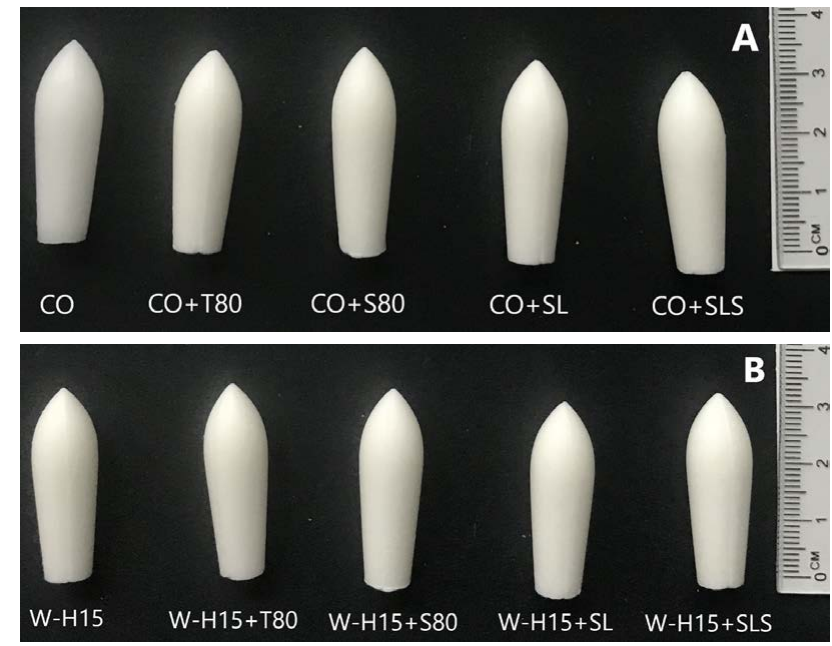

Fig. 3: Appearance of rectal suppositories prepared

The appearance of rectal suppositories prepared with $A$. cacao oleum and B. Witepsol H15

form of appropriate quality and stability than in the case of synthetic and semi-synthetic bases ${ }^{[27]}$. Literature supports successful use of Witepsol H15 bases as a suppository base $\mathrm{e}^{[9,11,28,29]}$.

In order to improve the rate and extent of release of meloxicam from fatty bases, different kinds of surfactants with different HLBs (hydrophiliclipophilic balance) ranging from 4.3 to 40 were used: amphoteric-soy lecithin $(\mathrm{HLB}=8)$, non-ionic-Span $80(\mathrm{HLB}=4.3)$, Tween $80(\mathrm{HLB}=15)$, and the anionic surfactant SLS $(\mathrm{HLB}=40)$. All these surfactants were added at $2 \%$ concentration, in order to be safe for rectal administration $^{[30]}$.

Under physiological conditions, drug particles must dissolve in the rectum mucosa, to be transported through its complex structure to enter the systemic circulation $^{[7]}$. Absorption of drugs from suppositories takes place through the rectal mucosa, which is highly vascularised within the upper and lower rectal veins. The rectal region is extensively drained by the lymphatic circulation and could increase the systematic absorption of some highly lipophilic drugs.

Realdon et al. ${ }^{[9]}$ demonstrated a strict relationship between the solubility of a drug in water and its dissolution rate from lipophilic suppositories in vitro. A drug with low water solubility saturates at the intrarectal phase at a low concentration, hindering the subsequent dissolution of the drug particles remaining in the melted excipient.

Surfactants are reported to improve drug dispersion into hard fatty excipients, increasing the spread of the melted suppository on rectal mucosa and leading to a greater contact surface, to reduce the viscosity of the molten mass and to reduce the pathway of drug particles to the interface ${ }^{[28]}$. These may enhance the intestinal absorption of some drugs by inhibiting an apically polarized efflux mechanism ${ }^{[31]}$. The presence of surfactants in concentrations around the critical micelle concentration does not promote or prolong drug release because of micellar entrapment of the drug ${ }^{[11]}$.

The results obtained in this study showed the effect of both the type of lipid base and the surfactant introduced into the suppository mass on the amount of meloxicam released. The release of meloxicam from the Witepsol H15 base was remarkably higher that from the Cacao oleum. This could be due to the presence of an emulsifying agent (glyceryl stearate) in the suppositories' bases, facilitating the dispersion of the active agent into the surrounding medium. The study showed that the release process from suppositories with an addition of surfactants goes faster in comparison with suppositories without surfactants. Incorporation of surfactants in the amount of $2 \% \mathrm{w} / \mathrm{w}$ to a suppository's mass did not cause a complete release of meloxicam 
from suppositories after $2 \mathrm{~h}$ of testing. Considering the site of application, which is the rectum, this time period initially seemed optimal for observing the release rate of the active drug substance (which can exert both general and local, e.g., analgesic and antiinflammatory effects).

In addition, a surfactant's type also has a significant influence on the release kinetics of the active drug substance. The highest release rate of the drug was observed for the formulation prepared on a Witepsol H15 base with the addition of Tween 80. From this formulation, $63.66 \%$ of meloxicam was released after $2 \mathrm{~h}$.

The results obtained are consistent with those achieved during another study on the active substance release from suppositories in the presence of a given surfactant. The study carried out by Abd el-Gawad et al. proved a positive influence of the surfactants (Tween 20, Tween 80 and Myrj 53) on the release of sulfamethoxazole from fatty bases (Witepsol H15) ${ }^{[29]}$. Hanaee et al. ${ }^{[28]}$ showed that Tween $80(2 \% \mathrm{w} / \mathrm{w})$ as well as SLS $(0.75 \% \mathrm{w} / \mathrm{w})$ caused an increase in the dissolution rate of salbutamol from suppositories formulated on a Witepsol H15 base. On the basis of this study, its suggested that Tween 80 should be added to suppository formulation in order to increase the dissolution rate of salbutamol. As anionic surfactants, such as SLS, cause greater damage to mucosa than non-ionic ones, such as Tween 80 , this study recommended that Tween 80 could be added in suppository formulation in order to increase the dissolution rate of salbutamol.

The addition of Tween 80 to Witepsol H15 had a maximal effect on naproxen release rate enhancement and thus $100 \%$ of the drug was released in $30 \mathrm{~min}$. The enhancement effect was seen to a lesser extent by adding SLS ${ }^{[11]}$. A slight effect from SLS on the release rate was also observed with mebeverine hydrochloride suppositories $^{[32]}$.

The release of paracetamol from suppositories prepared using Witepsol H15 decreased markedly in the presence of Span 60 (HLB 4.7) but increased in the presence of Span 20 (HLB 8.6). The addition of the most hydrophilic surfactant, Tween 20 (HLB 16,7), increases drug release, independently from surfactant concentration $(1 \text { or } 5 \%)^{[6]}$. In another study carried out by Adegboye and Itiola ${ }^{[21]}$ it was concluded that Tween 80 and sodium salicylate can be employed to formulate immediate-release suppositories with metronidazole. The effect of incorporating Tween 60 and Span 20 on the release rate of the fenoterol hydrobromide from
Witepsol H15 was investigated by Ghorab et al. ${ }^{[14]}$. The results showed very fast drug release when the drug was incorporated in Witepsol $\mathrm{H} 15$ as an aqueous solution. According to the authors ${ }^{[14]}$, the optimum concentration of Tween 60 is $5 \%$; above $10 \%$ the release rate is decreased due to micelle formation. Surfactants not only enhance release of the drug from the suppository base but increase the permeability of the tissues surrounding the rectal lumen. Non-ionic surfactant Tween 20 showed outstanding effectiveness used in a $5 \%$ concentration combined with lipophilic vehicles.

Incorporation of the surfactants Tween $80(0.5 \%)$ or Span $80(2 \%)$ facilitated and increased the release of paracetamol from the Suppocire S2 and the PEG $1500 / 4000$ bases into the dissolution medium, while with the use of Tween 40 in the Suppocire, $100 \%$ of the drug was released within $15 \mathrm{~min}^{[27]}$.

The release of meloxicam from the suppositories was carried out over $120 \mathrm{~min}$. However, according to our observations, this time wasn't sufficient to release the whole amount of the drug from the suppository. Therefore, it seems advisable to carry out further studies, in order to optimize the composition of the suppository mass (e.g., considering the suppository formulations from which the highest amount of the active drug substance was released). The present results could help in preparing suppository formulations, including the medication's dosage (concentration), which is welladjusted to the patient's individual health-related needs.

The prepared suppositories containing meloxicam can constitute an alternative route of administration from oral preparations, especially for the substances from the NSAID group with a significant first-pass effect. The results obtained confirmed the validity of the addition of surfactants to suppositories containing poorly soluble substances from the NSAID group.

\section{REFERENCES}

1. Mallick S, Dey PK, Sannigrahi S, Mitra A.Crystallization of a non-steroidal anti-inflammatory drug from ethanolwater solution in presence of polymers: physicochemical characterization and release behaviour from suppositories. Acta Pol Pharm 2004;61(6):447-53.

2. Mallick S, Sahu A, Pal K. Dissolution behaviour of nalidixic acid solid dispersions using water soluble dispersion carriers. Acta Pol Pharm 2004;61(1):21-30.

3. Hussaini A, Solorio D, Young C. Pharmacokinetic properties of low-dose SoluMatrix meloxicam in healthy adults. Clin Rheumatol 2016;35(4):1099-04.

4. Jafar M, Sadath A. Studies on meloxicam solid dispersion 
incorporated buccal patches. J App Pharm Sci 2011;01(03):7782.

5. Asghar W, Jamali F. The effect of COX-2-selective meloxicam on the myocardial, vascular and renal risks: a systematic review. Inflammopharmacology 2015;23(1):1-16.

6. Yazdanian M, Briggs K, Jankovsky C, Hawi A. The "high solubility" definition of the current FDA Guidance on Biopharmaceutical Classification System may be too strict for acidic drugs. Pharm Res 2004;21(2):293-99.

7. Machado TC, Gelain AB, Rosa J, Cardoso SG, Caon T. Cocrystallization as a novel approach to enhance the transdermal administration of meloxicam. Eur J Pharm Sci 2018;123:184-90.

8. Dal Zorro M, Franceschinis E, Punchina A, Realdon N. Effect of the surfactant on the availability of piroxicam as a poorly hydrosoluble drug from suppositories. Pharmazie 2012;67(1):37-45.

9. Realdon N, Dal Zotto M, Morpurgo M, Franceschinis E. Effects of surfactant characteristics on drug availability from suppositories. Pharmazie 2008;63(6),459-63.

10. Carrabba M, Paresce E, Angelini M, Galanti A, Marini MG, Cigarini P. A comparison of the local tolerability, safety and efficacy of meloxicam and piroxicam suppositories in patients with osteoarthritis: a single-blind, randomized, multicentre study. Curr Med Res Opin 1995;13(6):343-55.

11. Hargoli S, Farid J, Azarmi SH, Ghanbarzadeh S, ZakeriMilani P. Preparation and in vitro evaluation of naproxen suppositories. Indian J Pharm Sci 2013;75(2):143-48.

12. Swamy PV, Mohammed Younus Ali, Anand Kumar Y, Prasad K, Srinivaslu N. Design and evaluation of rectal drug delivery systems of non-steroidal anti-inflammatory drug. Int Curr Pharm J 2012;1(7):165-70.

13. Kalmár É, Ueno K, Forgó P, Szakonyi G, Dombi G. Novel sample preparation method for surfactant containing suppositories: effect of micelle formation on drug recovery. J Pharm Biomed Anal 2013;83:149-56.

14. Ghorab D, Refai H, Tag R. Preparation and evaluation of fenoterol hydrobromide suppositories. Drug Discov Ther 2011;5(6):311-18.

15. Sah ML, Saini TR. Formulation Development and Release Studies of Indomethacin Suppositories. Indian J Pharm Sci 2008;70(4):498-01.

16. Gadomska-Nowak M, Szulc-Musioł B, Jankowski A. The release of meloxicam from rectal suppositories depending on the applied suppository bases. Farm Pol 2010;66(8):536-38.

17. Jankowski A, Gadomska-Nowak M. Influence of surfactants on the carbamazepine absorption process in vitro. Farm Pol 2004;60(3):130-04.
18. Polish Pharmacopoeia, 11th ed., Warsaw, Poland: The President of the Office for Registration of Medicinal Products, Medical Devices and Biocidal Products; 2017.

19. Mallick S, Gupta BK, Ghosal SK. A study on the release kinetics of verapomil hydrochloride from microcapsules. Acta Pol Pharm 1999;56(4):297-02.

20. Mallick S, Gupta BK, Ghosal SK. Develop and characterization of release profile of nifedipine as an effect controlled release system. J Sci Ind Res 1999;58:1010-16.

21. Adegboye TA, Itiola OA. Physical and Release Properties of Metronidazole. Trop J Pharm Res 2008;7(1):887-96.

22. DeBoer GA, Moolenaar F, DeLeede LGJ, Breimer DD. Rectal drug administration: clinical pharmacokinetic considerations. Clin Pharmacokinet 1982; 7:285-11.

23. Moolenaar F; Meyler P, Frijlink E, Jauw TH, Visser J, Proost H. Rectal absorption of morphine from controlled-release suppositories. Int J Pharm 1995;114:117-20.

24. Ivaturi V, Kriel R, Brundage R, Loewen G, Mansbach H, Cloyd J. Bioavailability of intranasal vs. rectal diazepam. Epilepsy Res 2013;103:254-61.

25. Schneeweis A, Müller-Goymann CC. In vivo and in vitro diclofenac sodium evaluation after rectal application of soft gelatine capsules enabling application induced transformation (AIT) into a semisolid system of liquid crystals (SSLC) for controlled release. Pharm Res 1997;14(12):1726-29.

26. Maciejwska A, Niwiński K, Jaworski B, Jachowicz R. Opimization of compondended drug. Farm Pol 2017;73(12):746-53.

27. Ilomuanya MO, Ifudu D, Odulaja C. Assessment of the effect of base type and surfactant on the release properties and kinetics of paracetamol suppositories. J Chem Pharm Res 2012;4(6):3280-86.

28. Hanaee J, Javadzadeh Y, Taftachi S, Farid D, Nokhodchi A. The role of various surfactants on the release of salbutamol from suppositories. Farmaco 2004;59(11):903-6.

29. Abd el-Gawad AH, el-Din EZ, Abd el-Alim HA. Effect of surfactant incorporation techniques on sulphamethoxazole suppository formulations. Pharmazie 1988;43(9):624-7.

30. Oladimeji A, Omoruyi SI, Onyeji CO. Preparation and in vitro evaluation of suppositories of halofantrine hydrochloride. Afr J Biotechnol 2006;5(19):1775-80.

31. Berkó S, Regdon G Jr, Ducza E, Falkay G, Erós I. In vitro and in vivo study in rats of rectal suppositories containing furosemide. Eur J Pharm Biopharm 2002;53(3):311-15.

32. Al-Dossary BN, Al-Gohary ON, El-Khawaas MM. In vitro and in vivo availability of mebeverine hydrochloride suppositories. Sci Pharm 2006;74(1):31-51. 